\title{
PHOBIA AND COUNTERPHOBIA
}

PAUL HELLWEG

Northridge, California

Two wrongs are rumored to make things right, but do two phobias cancel each other out? For example, if a claustrophobe (one who fears closed spaces) were to become agoraphobic (fear of open spaces), would he be cured? Or would he simply have no place to go? Perhaps this is a fool's question, but the point is that a lot of phobias have direct opposites. (Not all phobias, however, have a counterpart. Many of us have ballistophobia - fear of being shot, but do you know anyone with a fear of not being shot?)

Below are two sets of ten phobias each. Each phobia in the first group has an opposite in the second group. See how many pairs of opposites you can match. Since some of these terms may be new to you, each has been provided with a clue. Good luck, have fun, and don't worry about atychiphobia (fear of failure).

1. Cathisophobia(a good way to save money on furniture)

2. Anuptaphobia (forget about joining a monastery or convent)

3. Homophobia (it would be a dull world if it weren't for these)

4. Amaxophobia (not for Los Angeles commuters)

5. Hypophobia (Winston Churchill would approve of this)

6. Monophobia (not for hermits)

7. Stygiophobia (an inducement to be on good behavior)

8. Chrematophobia (not for Howard Hughes)

9. Heliophobia (not found among beach-goers)

10. Thermophobia (these make poor firemen)

A. Ambulophobia (shoe salesmen dislike these)

B. Stasiphobia (it's hard to get up in the world with this)

C. Gamophobia (Zsa Zsa Gabor wasn't one)

D. Peniaphobia (not for struggling students, authors, artists)

E. Ochlophobia (not for party-goers)

F. Tropophobia (some conservative politicians have this fear)

G. Uranophobia (not for the Moral Majority)

H. Psychrophobia (Admiral Peary wasn't one)

l. Noctiphobia (not found amongst vampires)

J. Panphobia (do you know someone with all the above fears?)

Answers can be found in Answers and Solutions at the end of this issue. 